\title{
FAKTOR RISIKO EKSTERNAL KEJADIAN PHLEBITIS PADA PEMASANGAN KATETER INTRAVENA PERIFER: STUDI DOKUMENTASI
}

\author{
Ester Jois Maragani ${ }^{1}$, Fourini Marethalia ${ }^{2}$, Laura Margareth ${ }^{3}$, \\ Ni Gusti Ayu Eka**, Gracia Aktri M. Manihuruk ${ }^{5}$ \\ ${ }^{1-5}$ Fakultas Keperawatan, Universitas Pelita Harapan Tangerang \\ *Email: gusti.eka@uph.edu
}

Masuk : 26-05-2021, revisi: 24-09-2021, diterima untuk diterbitkan : 05-10-2021

\begin{abstract}
ABSTRAK
Terapi pemasangan intravena yang diberikan dalam jangka waktu yang lama dapat menimbulkan komplikasi seperti adanya kejadian phlebitis. Phlebitis adalah reaksi peradangan pada pembuluh darah vena beserta dengan tanda-tanda nyeri, kemerahan, bengkak, panas, serta pengerasan pada daerah tusukan dan sepanjang pembuluh darah vena. Salah satu faktor utama yang memengaruhi kejadian phlebitis adalah faktor eksternal seperti ukuran kateter intravena/IV yang tidak sesuai, lama pemasangan kateter IV, lokasi pemasangan kateter IV, pH dan osmolaritas cairan. Faktor lainnya yaitu faktor internal seperti usia, jenis kelamin dan penyakit penyerta. Faktor eksternal merupakan faktor yang dapat di modifikasi sesuai kewenangan perawat, sehingga dapat menurunkan angka kejadia phlebitis di rumah sakit. Tujuan penelitian ini untuk mengidentifikasi faktor risiko eksternal kejadian phlebitis pada pemasangan kateter intravena perifer di ruang rawat inap di satu rumah sakit swasta Indonesia. Metode penelitian ini adalah deskriptif kuantitatif. Sampel berdasarkan populasi, yang didapatkan dari rumus Slovin adalah 95 rekam medis pasien rawat inap dengan teknik purposive sampling. Pengumpulan data yang didapatkan dari dokumen rekam medis di masukkan dalam lembar observasi. Penelitian ini menunjukkan bahwa lebih separuh pasien yang terpasang kateter intravena mengalami kejadian phlebitis (53\%). Pasien yang mengalami kejadian phlebitis tersebut menggunakan ukuran kateter intravena 24G $(88,89 \%)$, lokasi pada metacarpal (56,33\%), menggunakan jenis cairan hipotonik $(81,25 \%)$ serta terpasang kateter intravena lebih atau sama dengan tiga hari $(63,41 \%)$. Penting untuk dapat meningkatkan pengetahuan dan keterampilan perawat khususnya tentang standar prosedur pemasangan infus dan perawatannya serta faktor eksternal yang memengaruhi terjadinya phlebitis.
\end{abstract}

Kata Kunci: Terapi intravena; Phlebitis; Faktor eksternal

\begin{abstract}
Intravenous insertion therapy given for a long time can cause complications such as phlebitis. Phlebitis is an inflammatory reaction in the veins along with signs of pain, redness, swelling, heat, and hardening at the puncture site and along the vein. One main factor that influence the incidence of phlebitis are external factors such as inappropriate intravenous (IV) catheters, length of catheter insertion, location of the catheter, $\mathrm{pH}$ and fluid osmolarity and internal factors include age, sex and comorbidities. External factors are factors that can be modified according to the authority of the nurse, so that the modification can reduce the incidence of phlebitis in the hospital. The aim of this study was to identify the external risk factors for phlebitis on peripheral intravenous catheter insertion in the inpatient room of a private Indonesian hospital. This research method was descriptive quantitative. Samples based on population, obtained from the Slovin formula were 95 medical records of inpatients with purposive sampling technique. Data collection obtained from medical record documents, included in the observation sheet. This study showed that more than half of the patients with intravenous catheters had the incidence of phlebitis (53\%). Patients who experienced the incidence of phlebitis used an intravenous catheter size of $24 G(88,89 \%)$, the location was in the metacarpal (56,33\%), used hipotonic fluid (81,25\%) and had an intravenous catheter inserted for more or equal to three days $(63,41 \%)$. It is important to be able to increase the knowledge and skills of nurses, especially regarding the standard procedure for infusion and treatment as well as external factors that influence the occurrence of phlebitis.
\end{abstract}

Keywords: Intravenous therap; Phlebitis; Eksternal factors 


\section{PENDAHULUAN}

Terapi intravena (IV) adalah proses menggunakan jarum infus yang dimasukkan ke dalam pembuluh darah vena kemudian disambungkan dengan selang infus yang digunakan untuk mengalirkan cairan infus (Gargar, Cutamora, \& Abocejo, 2017). Tujuan pemasangan terapi intravena yaitu untuk mengganti cairan tubuh yang hilang, jalur pemberian obat, pemberian transfusi darah, atau pengambilan sampel darah (Infusion Nurses Society, 2011). Oleh karena itu, pasien yang mendapatkan terapi intravena (IV) sebagian besar merupakan pasien yang harus rawat inap.

Terapi intravena yang diberikan kepada klien dalam jangka waktu yang cukup lama dapat menyebabkan komplikasi, yaitu terjadinya infeksi nosokomial. Infeksi nosokomial adalah infeksi yang berasal dari lingkungan rumah sakit dan terjadi karena adanya transmisi mikroba patogen (Khan, Baig, \& Mehboob, 2017). Salah satu bentuk dari infeksi nosokomial adalah phlebitis yaitu reaksi peradangan pada pembuluh darah vena beserta dengan tanda-tanda nyeri, kemerahan, bengkak, panas, serta pengerasan pada daerah tusukan dan sepanjang pembuluh darah vena (Infusion Nurses Society, 2011). Phlebitis merupakan peradangan yang terjadi pada vena dan dapat menyebabkan pembentukan trombus (Royal College of Nursing, 2010).

Angka kejadian phlebitis di rumah sakit pemerintah Indonesia sebesar 50,11\% dan 32,70\% untuk rumah sakit swasta (Badan Penelitian dan Pengembangan Kesehatan, 2013). Infeksi nosokomial di salah satu ruangan RSUD Ambarawa juga tercatat sebanyak 33 kejadian yang meliputi 30 kejadian phlebitis dan tiga kejadian dekubitus (Lindayanti \& Priyanto, 2013). Terdapat dua faktor utama yang memengaruhi kejadian phlebitis yaitu faktor eksternal dan faktor internal. Faktor eksternal meliputi ukuran kateter intravena (IV) tidak sesuai, lama pemasangan kateter, lokasi pemasangan kateter, $\mathrm{pH}$ dan osmolaritas cairan (Infusion Nurses Society, 2011). Faktor internal antara lain usia, jenis kelamin dan penyakit penyerta (Milutinović, Simin, \& Zec, 2015).

Penelitian yang dilaksanakan di lembaga pelayanan kesehatan tingkat tiga di kota Bucaramanga, Colombia (Rojas-Sánchez, Parra, \& Camargo-Figuera, 2015) menunjukkan bahwa insiden kumulatif phlebitis terkait dengan kateter intravena perifer adalah 10,1\%. Penelitian yang dilakukan sebelumnya (Herlina \& Jafa, 2018) dengan jumlah sampel 160 pasien mendapatkan hasil bahwa faktor risiko eksternal yang paling sering menyebabkan terjadinya kejadian phlebitis adalah ukuran kateter intravena, jenis cairan, lokasi pemasangan kateter intravena, dan lama infus terpasang.

Selain itu, hasil penelitian yang dilakukan di Rumah Sakit Imelda Medan (Komaling, Kumaat, \& Onibala, 2014) mengidentifikasi bahwa dari pasien yang mengalami pemasangan infus lebih dari 72 jam ( $\geq 3$ hari), terdapat $16(27,6 \%)$ yang mengalami phlebitis. Selain itu, empat $(6,9 \%)$ dari 37 pasien mengalami phlebitis dengan pemasangan infus 48-72 jam atau $\leq 3$ hari (Komaling et al., 2014). Oleh karena itu, dapat dinyatakan bahwa salah satu penyebab kejadian phlebitis adalah lamanya pemasangan infus.

Penelitian lainnya (Fitriyanti, 2015) melaporkan faktor eksternal dapat memengaruhi terjadinya phlebitis di Rumah Sakit Bhayangkara Surabaya. Faktor tersebut antara lain jenis cairan infus dan ukuran kateter intravena. Pasien yang mendapatkan terapi cairan infus hipertonik mengalami 
phlebitis sebanyak 17 orang (25\%). Sebanyak 12 orang $(17,6 \%)$ pasien menggunakan jarum berukuran $\leq 18$ yang mengalami phlebitis, sedangkan pada pasien dengan jarum berukuran $>18$ terdapat sepuluh orang $(14,7 \%)$ yang menderita phlebitis. Penelitian lain (Lindayanti \& Priyanto, 2013) juga melaporkan bahwa terdapat hubungan yang signifikan antara lokasi pemasangan kateter intravena dan kejadian phlebitis di RSUD Ambarawa ( $\mathrm{p}$ value 0,027). Berdasarkan lokasi pemasangan kateter intravena banyak terjadi phlebitis pada vena distal sebanyak lima responden $(45,5 \%)$. Saat ini diyakini bahwa penyebab utama phlebitis adalah stimulasi mekanik dari dinding pembuluh darah oleh jarum kateter intravena yang berdiam di dalam pembuluh darah dan cairan yang masuk dapat menyebabkan kerusakan mekanis pada pembuluh darah yang dapat menyebabkan reaksi inflamasi di dinding vena (Lu, Hao, He, Tang, \& Shao, 2018).

Tujuan penelitian ini adalah untuk mengidentifikasi faktor risiko eksternal kejadian phlebitis pada pemasangan kateter intravena perifer di ruang rawat inap di satu rumah sakit swasta Indonesia. Faktor risiko eksternal phlebitis yang diidentifikasi yaitu ukuran kateter intravena (IV), lama pemasangan kateter, lokasi pemasangan kateter, serta $\mathrm{pH}$ dan osmolaritas cairan.

\section{METODE PENELITIAN}

Metode penelitian ini menggunakan deskriptif kuantitatif (Polit \& Beck, 2018). Penelitian deskriptif ini bertujuan untuk mendapatkan gambaran faktor-faktor terjadinya kejadian phlebitis. Populasi penelitian ini adalah seluruh rekam medis pasien di ruang rawat inap di satu rumah sakit swasta di Indonesia Tengah dalam jangka waktu tiga bulan terakhir yaitu Januari-Maret 2019. Jumlah pasien di ruang rawat inap selama bulan Januari-Maret berjumlah 2.083 pasien. Berdasarkan rumus Slovin (nilai e 10\%), target sampel dalam penelitian ini adalah 95 rekam medis pasien rawat inap di satu rumah sakit swasta di Indonesia Tengah dengan menggunakan teknik purposive sampling. Kriteria inklusi penelitian ini adalah data rekam medis pasien yang terpasang kateter intravena di ruang rawat inap dalam jangka waktu saat pengambilan data dilakukan. Kriteria eksklusi penelitian ini adalah data rekam medis di ruang rawat jalan.

Instrumen yang digunakan adalah dokumentasi lembar check list yang dimodifikasi dari penelitian sebelumnya (Anggita, 2013). Instrumen ini dimodifikasi untuk mengetahui kondisi ada tidaknya phlebitis pada pasien, ukuran kateter intravena, lokasi pemasangan, keasaman cairan infus dan lama terpasangnya kateter intravena. Informasi tersebut dilakukan dengan melihat catatan perkembangan terintegritas direkam medis pasien. Kejadian phlebitis dilakukan dengan melihat catatan perkembangan terintegritas dari hari pertama pemasangan kateter intravena sampai hari ketiga. Adapun untuk mengetahui tanda-tanda phlebitis dapat dilihat dari Visual Infusion Phlebitis Score (VIP Score) untuk menilai skor visual pada phlebitis (Infusion Nurses Society, 2011).

\section{HASIL DAN PEMBAHASAN}

Pengumpulan data menggunakan purposive sampling, didapatkan 95 data rekam medis pasien di ruang rawat inap sesuai kriteria inklusi dan kriteria ekslusi yang ada. Seluruh data rekam medis pasien yang diteliti adalah pasien yang terpasang kateter intravena perifer di ruang rawat inap di satu rumah sakit swasta di Indonesia Tengah. Berikut ini hasil penelitian yang di paparkan dalam Tabel 1. 
Tabel 1 Faktor Eksternal Phlebitis

\begin{tabular}{lcccccc}
\hline \multirow{2}{*}{\begin{tabular}{c} 
Faktor eksternal \\
\multicolumn{1}{c}{ phlebitis }
\end{tabular}} & \multicolumn{2}{c}{ Phlebitis } & \multicolumn{2}{c}{ Non-Phlebitis } & \multicolumn{2}{c}{ Total } \\
\cline { 2 - 7 } & $\mathrm{N}$ & $\%$ & $\mathrm{~N}$ & $\%$ & $\mathrm{~N}$ & $\%$ \\
\hline Kejadian phlebitis & 50 & $53 \%$ & 45 & $47 \%$ & 95 & $100 \%$ \\
\hline $\begin{array}{l}\text { Ukuran kateter } \\
\text { intravena }\end{array}$ & & & & & & \\
$24 \mathrm{G}$ & 16 & 88,89 & 2 & 11,11 & 18 & $100 \%$ \\
$22 \mathrm{G}$ & 19 & 45,24 & 23 & 54,76 & 42 & $100 \%$ \\
$20 \mathrm{G}$ & 15 & 42,86 & 20 & 57,14 & 35 & $100 \%$ \\
\hline Lokasi pemasangan & & & & & & \\
Vena metacarpal & 40 & 56,33 & 31 & 43,67 & 71 & $100 \%$ \\
Vena sefalika & 10 & 41,67 & 14 & 58,33 & 24 & $100 \%$ \\
\hline pH dan osmolaritas cairan & & & & & & \\
Isotonik & 36 & 46,15 & 42 & 53,85 & 78 & $100 \%$ \\
Hipotonik & 13 & 81,25 & 3 & 18,75 & 16 & $100 \%$ \\
Hipertonik & 1 & 100 & 0 & 0 & 1 & $100 \%$ \\
\hline Lama pemasangan & & & & & & \\
$\geq 3$ Hari & 26 & 63,41 & 15 & 36,59 & 41 & $100 \%$ \\
$<3$ Hari & 24 & 44,44 & 30 & 55,56 & 54 & $100 \%$ \\
\hline
\end{tabular}

Berdasarkan data dokumentasi pada 95 pasien menunjukan bahwa pasien yang terpasang kateter intravena mengalami kejadian phlebitis sebanyak 50 pasien (53\%). Phlebitis merupakan salah satu komplikasi dari pemasangan kateter IV yang disebabkan oleh peradangan pada pembuluh darah vena. Peradangan yang ditimbulkan disebabkan oleh iritasi kimia dan mekanik (Infusion Nurses Society, 2011). Tanda dan gejala adanya phlebitis bisa muncul satu atau lebih seperti munculnya kemerahan, nyeri, indurasi, adanya pembengkakkan dan teraba hangat atau panas pada area penusukan (Infusion Nurses Society, 2011). Faktor eksternal yang dapat memengaruhi kejadian phlebitis meliputi: ukuran kateter intravena (IV), lama pemasangan kateter, lokasi pemasangan kateter, $\mathrm{pH}$ dan osmolaritas cairan (Infusion Nurses Society, 2011) yang juga di identifikasi dalam penelitian ini.

Berkaitan dengan ukuran kateter IV, hasil penelitian ini menunjukan bahwa pasien yang terpasang kateter intravena paling banyak menggunakan ukuran kateter IV 24G mengalami phlebitis sebanyak 88,89\%. Hasil penelitian yang dilakukan sebelumnya (Agustianingsih, Suryani, \& Astuti, 2015) tidak mendukung yaitu pasien yang mengalami phlebitis di rawat inap RS Panti Wilasa Citarum Semarang menggunakan ukuran 22 G (41,4\%). Pemakaian kateter IV harus disesuaikan dengan ukuran dan keadaan pembuluh darah vena. Jika pembuluh darah sangat tipis dan menggunakan kateter intravena yang tidak sesuai maka bisa merusak stuktur pembuluh darah (Infusion Nurses Society, 2011). Pertimbangan perawat dalam melakukan insersi yaitu pada vena yang kecil, tipis dan rapuh, tetesan harus lambat dan insersi akan sulit dilakukan pada kulit yang keras (Fitriyanti, 2015). Pada penelitian ini kejadian phlebitis yang terjadi mungkin karena ukuran kateter intravena tidak sesuai dengan ukuran vena pada pasien sehingga dapat mudah terjadi gesekan saat pasien bergerak sehingga dapat terjadi peradangan di sekitar area kateter IV. Menurut Stokowski et al. phlebitis bisa disebabkan karena adanya pergerakan benda asing (kateter intravena) yang tidak sesuai dengan ukuran vena sehingga menyebabkan gesekan dan peradangan didalam pembuluh darah vena (Stokowski, Steele, \& Wilson, 2009). 
Lokasi pemasangan kateter IV juga dapat meningkatkan terjadinya phlebitis oleh karena itu sebelum melakukan pemasangan kateter intravena harus memastikan pemilihan posisi yang tepat yaitu dengan mengukur jarak terlebih dahulu dan memilih ukuran kateter intravena yang sesuai dengan ukuran pembuluh darah (Amirullah, Erika, \& Patellongi, 2018). Faktor lain yang dapat memengaruhi atau meningkatkan terjadinya phlebitis, yaitu lokasi pemasangan, cairan infus bersifat asam atau memiliki osmolaritas tinggi dan lama pemasangan kateter intravena (Fitriyanti, 2015).

Pada penelitian ini juga didapatkan data pasien yang terpasang kateter intravena pada vena metacarpal mengalami phlebitis sebanyak 56,33\%. Hal ini didukung dengan hasil penelitian yang dilakukan oleh Sumara menunjukan bahwa pada 10 responden yang terpasang infus pada vena metacarpal, yaitu sekitar 25\% mengalami phlebitis (Sumara, 2017). Selain itu, phlebitis dapat disebabkan jika penempatan kateter intravena terlalu dekat dengan pergelangan tangan (vena metacarpal) karena hal ini dapat memudahkan terjadinya aliran balik darah (Nurjanah, Kristiyawati, \& Solechan, 2012). Vena metacarpal merupakan bagian ekstremitas yang sering digunakan, digerakan dan sebagai alat untuk motorik tubuh (Wayunah, Nurachmah, \& Mulyono, 2013). Terjadinya phlebitis dengan lokasi pemasangan kateter intravena pada vena metacarpal juga dapat dipengaruhi oleh jenis cairan yang diberikan kepada pasien (Infusion Nurses Society, 2011). Jika cairan yang diberikan berupa cairan isotonik maka dapat diberikan pada vena yang berukuran kecil. Tetapi jika pasien mendapatkan cairan yang bersifat iritatif maka dalam pemilihan ukuran IV perlu dipertimbangkan untuk menggunakan ukuran yang lebih besar.

Penelitian ini juga didapatkan data bahwa pasien yang terpasang kateter intravena menggunakan jenis cairan hipotonik mengalami phlebitis sebanyak 81,25\%. Hasil penelitian ini berbeda dengan penelitian sebelumnnya (Rizky, 2016) karena hasil penelitian menunjukan bahwa responden yang mengalami phlebitis menggunakan cairan hipertonik sebanyak 54\%. Selain itu, juga berbeda dengan penelitian Agustini et al. yang menunjukan hasil data bawah responden yang mengalami phlebitis dengan cairan hipertonik yaitu sebanyak 65\% (Agustini, Utomo, \& Agrina, 2013). Cairan hipotonik yang berlebihan dapat menjadi penyebab terjadinya "delusi cairan intravaskuler, penurunan tekandan darah, edema seluler dan kerusakan sel" (Rohani, 2016). Cairan hipotonik juga dapat menjadi penyebab terjadinya phlebitis jika disertai dengan adanya pemberian obat-obatan atau elektrolit yang ditambahkan di cairan hipotonik. Obat-obatan yang dapat menyebabkan phlebitis antara lain kalium klorida, obat antibiotik, diazepam, obat kemoterapi dan obat-obatan lain dengan osmolaritas >900 mOs/L yang diberikan melalui intravena (Infusion Nurses Society, 2011).

Berkaitan dengan lama pemasangan kateter IV, didapatkan data bahwa pasien yang terpasang kateter intravena dengan lama pemasangan $\geq 3$ hari mengalami phlebitis sebanyak $63,41 \%$. Hal ini didukung dengan hasil penelitian yang dilakukan oleh Herlina dan Jafa menunjukan bahwa lamanya infus terpasang yaitu $>3$ hari mengalami phlebitis yaitu sebanyak $13,75 \%$ (Herlina \& Jafa, 2018). Sama dengan penelitian yang dilakukan oleh Komaling et al. menunjukan terdapat 16 pasien $(27,6 \%)$ dengan lama pemasangan infus lebih dari 72 jam ( $\geq 3$ hari) mengalami phlebitis (Komaling et al., 2014). Pemasangan kateter intravena yang lamanya lebih dari tiga hari akan menyebabkan terjadi phlebitis karena bakteri dapat tumbuh pada area penusukan kateter intravena (Widani, 2018). The Center for Disease Control and Prevention menganjurkan untuk mengganti kateter intravena yang terpasang setiap ( $<3$ hari) untuk mengurangi terjadinya peradangan dan mencegah tumbuhnya bakteri (Centers for Disease Control and Prevention, 2011). 


\section{KESIMPULAN DAN SARAN}

Penelitian ini melaporkan bahwa lebih dari separuh pasien yang terpasang kateter intravena mengalami phlebitis dan terdapat faktor risiko eksternal yang dapat memengaruhi kejadian phlebitis. Faktor resiko eksternal yang dapat memengaruhi kejadian phlebitis antara lain ukuran kateter intavena 24G, lokasi pemasangan kateter pada vena metacarpal, jenis cairan hipotonik dengan tambahan obat-obatan dan lama pemasangan $>3$ hari. Sangat penting bagi perawat untuk memahami kembali SOP/Standard of Procedure rumah sakit khususnya tentang standar prosedur pemasangan infus dan perawatannya serta tentang faktor eksternal yang memengaruhi terjadinya phlebitis. Sehingga, perawat dapat memperhatikan dan mempertimbangkan faktor ekternal tersebut saat memilih lokasi pemasangan kateter intravena pada vena metacarpal. Rumah sakit juga diharapkan dapat memfasilitasi pelatihan perawat mengenai terapi intravena, perawatannya dan cara pencegahan phlebitis. Selain itu, perlu adanya tindak lanjut dari tim pengendalian infeksi nosokomial di rumah sakit, sehingga kejadian phlebitis dapat dicegah atau di atasi untuk peningkatan mutu pelayanan.

\section{Ucapan Terima Kasih}

Terima kasih kepada Fakultas Keperawatan Universitas Pelita Harapan dan rumah sakit swasta yang sudah mengijinkan untuk pelaksanaan penelitian ini.

\section{REFERENSI}

Agustianingsih, D., Suryani, M., \& Astuti, R. (2015). Hubungan ukuran kateter intravena dengan kejadian flebitis pasien rawat inap di RS Panti Wilasa Citarum Semarang. Jurnal Ilmu Keperawatan Dan Kebidanan, 4.

Agustini, C., Utomo, W., \& Agrina. (2013). Analisis faktor yang berhubungan dengan kejadian phlebitis pada pasien yang terpasang infus di ruang Medikal Chrysant Rumah Sakit Awal Bros Pekanbaru. Jurnal Online Mahasiswa Program Study Ilmu Keperawatan Universitas Riau.

Amirullah, Erika, K. A., \& Patellongi, I. (2018). Evaluasi Teknik Pemasangan Infus Dan Insiden Phlebitis Di Rsud H.a.Sulthan Daeng Radja Bulukumba. Jurnal Ilmiah Kesehatan Diagnosis.

Anggita, S. D. (2013). analisa faktor -faktor terhadap kejadia plebitis pada pasien yang medapatkan terapi cairan intravena (Di Ruang Melati Rumah Sakit Umum Daerah Bangil Tahun 2018). Journal of Chemical Information and Modeling.

Badan Penelitian dan Pengembangan Kesehatan. (2013). Riset Kesehatan Dasar (RISKESDAS) 2013. Laporan Nasional 2013. https://doi.org/1 Desember 2013

Centers for Disease Control and Prevention. (2011). Guidelines for the Prevention of Intravascular Catheter-Related Infections (2011). Retrieved from https://www.cdc.gov/infectioncontrol/guidelines/bsi/index.html

Fitriyanti, S. (2015). Faktor Yang Mempengaruhi Terjadinya Phlebitis Di. Faktor Yang Mempengaruhi Terjadinya Phlebitis Di Rumah Sakit Bhayangkara Tk Ii. H.S. Samsoeri Mertojoso Surabaya.

Gargar, A. P., Cutamora, J. C., \& Abocejo, F. T. (2017). Phlebitis, Infiltration, and Localized Site Infection Among Patients With Peripheral Intravenous Catheters. European Scientific Journal, ESJ. https://doi.org/10.19044/esj.2017.v13n18p148

Herlina, M., \& Jafa, A. G. P. (2018). Faktor-faktor yang Berhubungan dengan Kejadian Plebitis pada Pasien yang Terpasang Infus di Rumah Sakit Imelda Pekerja Indonesia (RSU IPI) Medan. Jurnal Ilmiah Keperawatan IMELDA.

Infusion Nurses Society. (2011). Infusion nursing standards of practice. Journal of Infusion Nursing, 34(1S). https://doi.org/10.1097/01.NAN.0000270673.13439.95 
Khan, H. A., Baig, F. K., \& Mehboob, R. (2017). Nosocomial infections: Epidemiology, prevention, control and surveillance. Asian Pacific Journal of Tropical Biomedicine. https://doi.org/10.1016/j.apjtb.2017.01.019

Komaling, C., Kumaat, L., \& Onibala, F. (2014). Hubungan lamanya pemasangan infus (intravena) dengan kejadian Flebitis pada pasien di IRINA F BLU RSUP Prof. Dr. R. D. Kandou Manado. Jurnal Keperawatan UNSRAT.

Lindayanti, N., \& Priyanto. (2013). Hubungan antara tehnik insersi dan lokasi pemasangan kateter intravena dengan kejadian phlebitis di Rsud Ambarawa. Jurnal Keperawatan Medikal Bedah.

Lu, Y., Hao, C., He, W., Tang, C., \& Shao, Z. (2018). Experimental research on preventing mechanical phlebitis arising from indwelling needles in intravenous therapy by external application of mirabilite. Experimental and Therapeutic Medicine. https://doi.org/10.3892/etm.2017.5347

Milutinović, D., Simin, D., \& Zec, D. (2015). Risk factor for phlebitis: A questionnaire study of nurses' perception. Revista Latino-Americana de Enfermagem. https://doi.org/10.1590/0104-1169.0192.2603

Nurjanah, D., Kristiyawati, S. P., \& Solechan, A. (2012). Hubungan antara Lokasi penusukan infus dan tingkat usia dengan kejadian flebitis di ruang rawat inap dewasa RSUD Tugurejo Semarang. Jurnal Ilmu Keperawatan Dan Kebidanan, 1(1).

Polit, D. ., \& Beck, C. . (2018). Essentials of Nursing Research: Appraising Evidence for Nursing Practice: Appraising evidence for nursing practice. In Wolters Kluwer.

Rizky, W. (2016). Analisis Faktor yang Berhubungan dengan Kejadian Phlebitis pada Pasien yang Terpasang Kateter Intravena di Ruang Bedah Rumah Sakit Ar. Bunda Prabumulih. Jurnal Ners Dan Kebidanan Indonesia. https://doi.org/10.21927/jnki.2016.4(2).102-108

Rohani. (2016). Hubungan Lama Pemasangan Infus dengan Terjadinya Phlebitis di RS Husada Jakarta Tahun 2015. Jurnal Ilmiah WIDYA.

Rojas-Sánchez, L., Parra, D., \& Camargo-Figuera, F. (2015). Incidence and factors associated with development of phlebitis: results of a pilot study cohort. Revista de Enfermagem Referência. https://doi.org/10.12707/riii13141

Royal College of Nursing. (2010). Standards for Infusion Therapy (fourth).

Stokowski, G., Steele, D., \& Wilson, D. (2009). The use of ultrasound to improve practice and reduce complication rates in peripherally inserted central catheter insertions: Final report of investigation. Journal of Infusion Nursing. https://doi.org/10.1097/NAN.0b013e3181a1a98f

Sumara, R. (2017). Hubungan Lokasi Terapi Intravenus Dengan Kejadian Plebitis. Jurnal Keperawatan Muhammadiyah. https://doi.org/10.30651/jkm.v2i1.926

Wayunah, W., Nurachmah, E., \& Mulyono, S. (2013). Pengetahuan Perawat Tentang Terapi Infus Mempengaruhi Kejadian Plebitis dan Kenyamanan Pasien. Jurnal Keperawatan Indonesia. https://doi.org/10.7454/jki.v16i2.12

Widani, N. luh. (2018). Pengaruh Penggantian Kateter Intravena dan Set Infus Terhadap Terjadinya Phlebitis. Jurnal Persatuan Perawat Nasional Indonesia (JPPNI). https://doi.org/10.32419/jppni.v3i1.98 
FAKTOR RISIKO EKSTERNAL KEJADIAN PHLEBITIS PADA

PEMASANGAN KATETER INTRAVENA PERIFER:

STUDI DOKUMENTASI

(halaman ini sengaja dikosongkan) 